\title{
Respiratory symptoms among infants at risk for asthma: association with surfactant protein A haplotypes
}

\author{
Melinda M Pettigrew*, Janneane F Gent, Yong Zhu, Elizabeth W Triche, \\ Kathleen D Belanger, Theodore R Holford, Michael B Bracken and \\ Brian P Leaderer
}

Address: Yale Center for Perinatal, Pediatric and Environmental Epidemiology, Department of Epidemiology and Public Health, Yale University School of Medicine, New Haven, CT, USA

Email: Melinda M Pettigrew* - melinda.pettigrew@yale.edu; Janneane F Gent - janneane.gent@yale.edu; Yong Zhu - yong.zhu@yale.edu; Elizabeth W Triche - elizabeth.triche@yale.edu; Kathleen D Belanger - kathleen.belanger@yale.edu;

Theodore R Holford - theodore.holford@yale.edu; Michael B Bracken - michael.bracken@yale.edu; Brian P Leaderer - brian.leaderer@yale.edu

* Corresponding author

Published: 2 April 2007

BMC Medical Genetics 2007, 8:15 doi:10.1186/147/-2350-8-15
Received: 24 October 2006

Accepted: 2 April 2007

This article is available from: http://www.biomedcentral.com/I47I-2350/8/15

(c) 2007 Pettigrew et al; licensee BioMed Central Ltd.

This is an Open Access article distributed under the terms of the Creative Commons Attribution License (http://creativecommons.org/licenses/by/2.0), which permits unrestricted use, distribution, and reproduction in any medium, provided the original work is properly cited.

\begin{abstract}
Background: We examined the association between single nucleotide polymorphisms (SNPs) in loci encoding surfactant protein A (SFTPA) and risk of wheeze and persistent cough during the first year of life among a cohort of infants at risk for developing asthma.

Methods: Between September 1996 and December 1998, mothers of newborn infants were invited to participate if they had an older child with clinician-diagnosed asthma. Each mother was given a standardized questionnaire within 4 months of her infant's birth. Infant respiratory symptoms were collected during quarterly telephone interviews at 6,9 and 12 months of age. Due to the association of SFTPA polymorphisms and race/ethnicity, analyses were restricted to 221 white infants for whom whole blood and respiratory data were available. Ordered logistic regression models were used to examine the association between respiratory symptom frequency and SFTPA haplotypes.
\end{abstract}

Results: The 6A allele haplotype of SFTPA I, with an estimated frequency of $6 \%$ among our study infants, was associated with an increased risk of persistent cough (OR 3.69,95\% Cl I.7I, 7.98) and wheeze (OR $4.72,95 \% \mathrm{Cl} 2.20,10.1 \mathrm{I})$. The 6A/I A haplotype of SFTPA, found among approximately

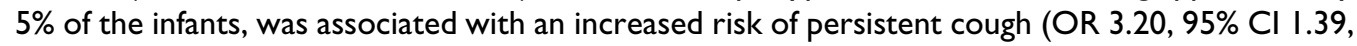
7.36) and wheeze (OR 3.25, 95\% Cl I.43, 7.37).

Conclusion: Polymorphisms within SFTPA loci may be associated with wheeze and persistent cough in white infants at risk for asthma. These associations require replication and exploration in other ethnic/racial groups.

\section{Background}

Wheeze and persistent cough in infants are serious respiratory symptoms that can be triggered by respiratory infec- tions and/or a variety of environmental exposures [1-3]. Surfactant protein A (SFTPA) is an abundant, multifunctional protein that is secreted by airway epithelial cells 
and functions as part of the innate immune response. SFTPA may be critical in protecting the lungs from infectious agents and environmental exposures early in life before the acquisition of specific immunity. SFTPA neutralizes respiratory viruses such as influenza and respiratory syncytial virus (RSV) [4,5]. SFTPA also enhances the uptake of bacteria and viruses by phagocytes [6-8]. In addition to its role in protecting the lungs from microorganisms, SFTPA has other important immunomodulatory functions including binding aeroallergens [9].

SFTPA's role in protection of the lungs has led to exploration of potential links between SFTPA and diseases of the respiratory tract in infants and young children. Polymorphisms within SFTPA1 and SFTPA2, two functional, highly homologous SFTPA genes [10-12] have been linked to respiratory distress syndrome in infants [13-15], severe RSV bronchiolitis [16], and otitis media [17,18]. In the present study, we used a candidate gene approach to investigate whether polymorphisms within the SFTPA1 and SFTPA2 genes were associated with wheeze and persistent cough during the first year of life among a prospective birth cohort at risk for developing asthma.

\section{Methods \\ Cohort}

Between September 1996 and December 1998, we invited women delivering babies in six hospitals in Connecticut and Massachusetts to participate in a longitudinal study of asthma development if they had at least one other child at home under 12 years of age with physician-diagnosed asthma. Infants enrolled in the cohort were considered at risk for asthma due to their asthmatic siblings. We provide a full description of the methods elsewhere [2,19].

Of the 1,002 infants originally enrolled, respiratory symptom data were available for the first year of life for 889 . Between the third and fifth year of participation, we made a second visit to the home to collect a blood sample from our cohort subjects. The current analyses are based on a convenience sample of 355 for whom whole blood and complete respiratory symptom data were available. Nucleotide changes at amino acid (aa) 19, aa 62, and aa 133 in SFTPA1, and aa 223 in SFTPA2 were significantly associated with ethnicity. To prevent identification of invalid associations due to population stratification, we restricted our haplotype analyses to the ethnic group with the largest number of subjects (221 white infants). The Yale Human Investigations Committee and institutional review boards at each participating hospital reviewed and approved the study.

\section{Data collection}

A research assistant visited the home within 4 months of the infant's birth in order to describe the study to the infant's mother, obtain written informed consent, and administer a standardized questionnaire. We collected household demographic data including maternal race and ethnicity, education and number of children; detailed information regarding infant care (e.g. breastfeeding and daycare use); and maternal health status (e.g. self-reported history of allergies or physician-diagnosed asthma). Infant respiratory symptoms were collected during quarterly telephone interviews at 6,9 and 12 months of age at which time each mother reported on her infant's respiratory symptoms (number of symptom-days per month of wheeze or persistent cough) and doctor or clinic visits (month and year of visit, reason for visit, and diagnosis). Around the time of the infant's first birthday, the mother completed an additional phone questionnaire covering her infant's health status during the previous year.

\section{Genotyping of SFTPA genes}

DNA was extracted from whole blood using the QIAamp DNA blood minikit (Qiagen) according to the manufacturer's instructions. We used sequence specific primerPCR methodology to genotype the SNPs at aa 19, aa 50, aa 62, aa 133, and aa 219 in SFTPA1 and aa 9, aa 91, aa 223 in SFTPA2 [20]. We used PCR based cRFLP as described by DiAngelo et al. [21] to detect polymorphisms in SFTPA2 at aa 140.

\section{Data analysis}

Outcomes of interest were respiratory symptom frequency in the first year of life categorized as none or as 1 to 7,8 to 14,15 to 21,22 to 28 , or more than 28 days of persistent cough or wheeze. Between 1 and 6 months of symptom information were missing for 18 infants. Data from these infants were included in analyses based on their symptom rates. All other infants had 12 months of complete symptom data. Unadjusted associations between respiratory symptoms and selected study characteristics, SNPs, and individual SFTPA1 or SFTPA2 alleles were evaluated with tests for linear trend (Cochran-Armitage or Somers' D statistic). For statistical tests involving SNPs, frequencies for the minor homozygous allele and heterozygous alleles were combined and compared to the dominant homozygous group. Observed SNP frequencies were tested for Hardy-Weinberg equilibrium by $\chi^{2}$ analyses. We examined pairwise linkage disequilibrium with $\mathrm{r}^{2}$ measures (Fig. 1) using PROC ALLELE of the SAS/Genetics module of SAS version 9.1 [22]. Allele haplotypes for SFTPA1 and for SFTPA2 were assigned and examined for linkage disequilibrium using PROC HAPLOTYPE [22]. We examined the association between haplotype and respiratory symptom frequency (as categorical variables) using ordered logistic regression. Separate analyses were 
conducted for each symptom and each haplotype compared to all other haplotypes. We estimated the effect of uncertainty in haplotype assignment using a regression calibration technique $[18,23]$ and the SFTPA1 and SFTPA2 haplotype probabilities obtained from PROC HAPLOTYPE. As described previously [18], this technique involved first creating 100 separate haplotype data sets by randomly assigning subject haplotypes based on each subject's haplotype probabilities. Next, 100 separate ordered logistic regression models with coefficient and variance estimates ( $\beta_{\mathrm{i}}$ and $\sigma_{\mathrm{i}}{ }^{2}$ for the $\mathrm{i}^{\text {th }}$ model $)$ were fit for each haplotype of interest. The estimate of the association between the respiratory symptom and the particular haplotype of interest ( $\hat{\beta}$ ) was calculated as the mean of the 100 regression models. The variability of the estimate was calculated as

$$
\operatorname{var}(\hat{\beta})=\operatorname{mean}\left(\sigma_{i}^{2}\right)+\operatorname{var}\left(\mathrm{b}_{\mathrm{i}} \mathrm{s}\right)
$$

where mean $\left(\sigma_{i}^{2}\right)$ is defined as the mean of the 100 logistic regression variances and $\operatorname{var}\left(b_{i} s\right)$ is defined as the variance of the 100 logistic regression b coefficients.

\section{Results}

Close to half of the 221 infants in our study experienced persistent cough $(51 \%)$ or wheeze $(46 \%)$ during their first year of life (Table 1). Thirty-two percent of the infants experienced from 1 to 28 days of persistent cough, 19\% experienced more than 28 days of persistent cough during their first year; $36 \%$ experienced 1 to 28 days of wheeze and $10 \%$ experienced more than 28 days of wheeze during their first year of life. Male infants and infants of asthmatic mothers were more likely to experience persistent cough and wheeze during their first year of life (Table 1). We did not find significant associations with either persistent cough or wheeze and maternal allergies, age daycare attendance began, number of months of breastfeeding, or exposure to environmental tobacco smoke (ETS).

Table 2 contains unadjusted associations between each of the nine candidate SNPs and persistent cough or wheeze. Individual SNPs were in Hardy-Weinberg equilibrium ( $\mathrm{p}$ $>0.05$ for the $\chi^{2}$ test). Having a $C$ nucleotide at aa 19 in SFTPA1 was associated with greater frequency of wheeze. The G nucleotide at aa 133 was associated with both wheeze and persistent cough during the first year of life. We did not find any significant associations between each of the nine SNPs and personal characteristics listed in Table 1.

\begin{tabular}{|c|c|c|c|c|c|c|c|c|c|}
\hline & aa 19 & aa 50 & aa 62 & aa 133 & aa 219 & aa 9 & aa 91 & aa 140 & aa 223 \\
\hline \multicolumn{10}{|l|}{ aa 19} \\
\hline aa 50 & 0.1 & & & & & & & & \\
\hline aа 62 & 0.3 & 0.2 & & & & & & & \\
\hline aa 133 & 0.5 & 0.1 & 0.3 & & & & & & \\
\hline aa 219 & 0.0 & 0.1 & 0.4 & 0.0 & & & & & \\
\hline aa 9 & 0.1 & 0.6 & 0.2 & 0.1 & 0.1 & & & & \\
\hline aа 91 & 0.3 & 0.2 & 0.5 & 0.5 & 0.1 & 0.2 & & & \\
\hline aa 140 & 0.0 & 0.2 & 0.1 & 0.0 & 0.1 & 0.3 & 0.0 & & \\
\hline aa 223 & 0.0 & 0.1 & 0.0 & 0.0 & 0.0 & 0.2 & 0.0 & 0.5 & \\
\hline
\end{tabular}

\begin{tabular}{|c|c|c|c|c|c|c|c|c|c|c|c|}
\hline $\mathrm{R}^{2}$ & 0 & 0.1 & 0.2 & 0.3 & 0.4 & 0.5 & 0.6 & 0.7 & 0.8 & 0.9 & 1 \\
\hline color & \multicolumn{10}{|c|}{} \\
\hline
\end{tabular}

Figure I

Pairwise linkage disequilibrium measure $\left(r^{2}\right)$ for surfactant protein A SNPs (5 SFTPAI SNPs: aa 19, aa 50, aa 62, aa I33, aa 219; 4 SFTPA2 SNPs: aa 9, aa 9I aa 140, aa 223) from 221 white infants at risk for developing asthma. Gray scale represents strength of association from white $\left(r^{2}=0\right)$ to black $\left(r^{2}=1\right)$. (CT and MA, $\left.1998-2000\right)$ 
Table I: Unadjusted associations between personal characteristics and respiratory symptoms during the first year of life for $22 \mathrm{I}$ white infants at risk for developing asthma. (CT and MA, $1998-2000)$

\begin{tabular}{|c|c|c|c|c|c|c|c|c|c|c|c|c|c|c|c|}
\hline \multirow[b]{2}{*}{ Characteristic } & \multirow[b]{2}{*}{ n (\%) } & \multicolumn{7}{|c|}{ Persistent cough (days/year) (\%) } & \multicolumn{7}{|c|}{ Wheeze (days/year) (\%) } \\
\hline & & 0 & I - 7 & $8-14$ & $|5-2|$ & $22-28$ & $>28$ & p-value ${ }^{a}$ & 0 & I - 7 & $8-14$ & $|5-2|$ & $22-28$ & $>28$ & p-value ${ }^{a}$ \\
\hline White infants $\mathbf{N}(\%)$ & 221 & $109(49.3)$ & $30(13.6)$ & $19(8.6)$ & $12(5.4)$ & $10(4.5)$ & $4 \mid(18.6)$ & & $119(54.3)$ & $49(22.4)$ & $17(7.8)$ & $7(3.2)$ & $6(2.7)$ & $21(9.6)$ & \\
\hline \multicolumn{16}{|l|}{ Gender } \\
\hline male & II $5(52.0)$ & 42.6 & 14.8 & 11.3 & 7.0 & 7.0 & 17.4 & 0.12 & 44.2 & 27.4 & 8.0 & 3.5 & 4.4 & 12.4 & 0.005 \\
\hline female & $106(48.0)$ & 56.6 & 14.3 & 5.7 & 3.8 & 1.9 & 19.8 & & 58.0 & 17.0 & 7.6 & 2.8 & 0.9 & 6.6 & \\
\hline \multicolumn{16}{|l|}{ Maternal allergies } \\
\hline No & 81 (36.7) & 44.4 & 17.3 & 8.6 & 3.7 & 2.5 & 23.5 & 0.20 & 52.5 & 21.2 & 10.0 & 3.8 & 2.5 & 10.0 & 0.35 \\
\hline Yes & $140(63.4)$ & 52.1 & 11.4 & 8.6 & 6.4 & 5.7 & 15.7 & & 55.4 & 23.0 & 6.5 & 2.9 & 2.9 & 9.4 & \\
\hline \multicolumn{16}{|l|}{ Maternal asthma } \\
\hline No & $153(69.2)$ & 52.3 & 15.0 & 9.2 & 5.2 & 2.0 & 16.3 & 0.02 & 57.2 & 23.7 & 7.9 & 2.6 & 0.7 & 7.9 & 0.01 \\
\hline Yes & $68(30.7)$ & 42.6 & 10.3 & 7.4 & 5.9 & 10.3 & 23.5 & & 47.8 & 19.4 & 7.5 & 4.5 & 7.5 & 13.4 & \\
\hline \multicolumn{16}{|l|}{$\begin{array}{l}\text { Daycare (starting } \\
\text { age in months) }\end{array}$} \\
\hline $1-5$ & $43(19.6)$ & 48.8 & 14.0 & 9.3 & 2.3 & 7.0 & 18.6 & 0.26 & 55.8 & 14.0 & 11.6 & 2.3 & 4.6 & 11.6 & 0.45 \\
\hline $6-12$ & $21(9.6)$ & 57.1 & 9.5 & 19.0 & 4.8 & 0.0 & 9.5 & & 55.0 & 30.0 & 10.0 & 0.0 & 0.0 & 0.5 & \\
\hline None in first year & $155(70.8)$ & 49.0 & 14.2 & 6.4 & 6.4 & 4.5 & 19.4 & & 53.9 & 24.0 & 6.5 & 3.9 & 2.6 & 9.1 & \\
\hline \multicolumn{16}{|l|}{$\begin{array}{l}\text { Breast feeding } \\
\text { (duration in } \\
\text { months) }\end{array}$} \\
\hline None & $49(22.3)$ & 53.1 & 14.3 & 6.1 & 4.1 & 0.0 & 22.4 & 0.25 & 49.0 & 18.4 & 10.2 & 2.0 & 6.1 & 14.3 & 0.15 \\
\hline $1-5$ & 57 (25.9) & 49.1 & 19.3 & 3.5 & 7.0 & 5.3 & 15.8 & & 57.9 & 19.3 & 3.5 & 3.5 & 1.8 & 14.0 & \\
\hline $6-12$ & II 4 (5I.8) & 47.4 & 10.5 & 12.3 & 5.3 & 6.1 & 18.4 & & 54.5 & 25.9 & 8.9 & 3.6 & 1.8 & 5.4 & \\
\hline \multicolumn{16}{|l|}{ ETS } \\
\hline No & $197(89.6)$ & 48.7 & 12.2 & 9.6 & 5.6 & 4.6 & 19.3 & 0.19 & 55.4 & 20.5 & 8.7 & 3.1 & 3.1 & 9.2 & 0.38 \\
\hline Yes & $23(10.4)$ & 52.2 & 26.1 & 0.0 & 4.4 & 4.4 & 13.0 & & 43.5 & 39.1 & 0.0 & 4.4 & 0.0 & 13.0 & \\
\hline
\end{tabular}

ap-values from test for trend: Cochran-Armitage exact test (I-sided) for gender, maternal allergies, maternal asthma, Environmental Tobacco Smoke (ETS); Somer's D statistic ( $\mathrm{I}$-sided) for age when starting daycare and duration of breastfeeding. Significant $p$-values $(p<0.05)$ in bold-face type. 
Table 2: Unadjusted associations between SNPs from surfactant protein A alleles (SFTPAI,SFTPA2) and respiratory symptoms ${ }^{\mathrm{a}}$ during the first year of life for white infants at risk for developing asthma. (CT and MA, 1998 - 2000)

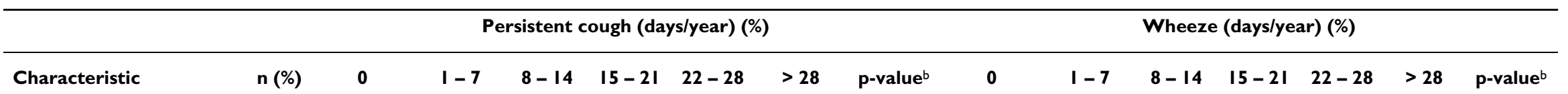

Characteristic

$221 \quad 109(49.3) \quad 30(13.6) \quad 19(8.6) \quad 12(5.4) \quad 10(4.5) \quad 41(18.6)$

$119(54.3) \quad 49(22.4) \quad 17(7.8) \quad 7(3.2) \quad 6(2.7) \quad 21(9.6)$

White infants $\mathbf{N}$ (\%)

SFTPAI

aa 19 (rs I 059047)

CC

I (0.4)

CT

42 (19.0)

46.5

TT

$178(80.5)$

$$
49.7
$$

7.0

$\begin{array}{ll}11.6 & 7.0 \\ 8.0 & 5.1\end{array}$

2.3

25.6

0.15

44.2
56.6

18.6

11.6

$\begin{array}{lll}4.6 & 7.0 & 14.0 \\ 2.9 & 1.7 & 8.7\end{array}$

aa 50 (rs I I36450)

CC

48 (21.4)

CG

GG

$$
103(46.0)
$$

51.7

$\begin{array}{ll}10.9 & 8.2 \\ 17.8 & 9.6\end{array}$

6.1
4.1

3.4
6.8

19.7
16.4

0.50

$\begin{array}{llllll}53.4 & 22.6 & 8.9 & 2.7 & 3.4 & 8.9 \\ 55.6 & 22.2 & 5.6 & 4.2 & 1.4 & 11.1\end{array}$

aa 62 (rsI I3645I)

GG

$$
5 \text { (2.2) }
$$

AG

AA

$$
61 \text { (27.5) }
$$

7.8
15.6

$\begin{array}{llll}14.1 & 6.2 & 3.1 & 23.4 \\ 6.5 & 4.6 & 5.2 & 16.9\end{array}$

0.11

$\begin{array}{ll}46.9 & 21.9 \\ 57.9 & 21.7\end{array}$

10.9
6.6

$\begin{array}{lll}3.1 & 6.2 & 10.9 \\ 3.3 & 1.3 & 9.2\end{array}$

aa 133

(rs 1059057)

GG

AG

AA

$$
\text { I (0.4) }
$$

$$
38 \text { (16.9) }
$$

36.8

186 (82.7)

51.9

7.9
14.8

$\begin{array}{llll}13.2 & 7.9 & 2.6 & 31.6 \\ 7.6 & 4.9 & 4.9 & 15.8\end{array}$

0.02

39.5
57.5

18.4
23.2

aa 219

(rs4253527)

TT

I (0.4)

CT

$$
34 \text { (15.1) }
$$

52.9

11.8

20.6

2.9

0.0

11.8


Table 2: Unadjusted associations between SNPs from surfactant protein A alleles (SFTPAI,SFTPA2) and respiratory symptoms ${ }^{\mathrm{a}}$ during the first year of life for white infants at risk for developing asthma. (CT and MA, 1998 - 2000) (Continued)

\begin{tabular}{|c|c|c|c|c|c|c|c|c|c|c|c|c|c|c|c|}
\hline $\mathrm{CC}$ & $190(84.4)$ & 48.7 & 13.9 & 6.4 & 5.9 & 5.4 & 19.8 & & 54.0 & 21.1 & 7.0 & 3.9 & 3.2 & 10.8 & \\
\hline \multicolumn{16}{|c|}{$\begin{array}{l}\text { aa } 9 \\
\text { (rs 1059046) }\end{array}$} \\
\hline $\mathrm{CC}$ & $42(18.7)$ & & & & & & & & & & & & & & \\
\hline$A C$ & $109(48.4)$ & 52.4 & 11.6 & 9.5 & 4.1 & 3.4 & 19.0 & 0.26 & 55.1 & 21.1 & 8.8 & 2.0 & 3.4 & 9.5 & 0.50 \\
\hline AA & 74 (32.9) & 43.2 & 17.6 & 6.8 & 8.1 & 6.7 & 17.6 & & 52.8 & 25.0 & 5.6 & 5.6 & 1.4 & 9.7 & \\
\hline \multicolumn{16}{|c|}{$\begin{array}{l}\text { aa } 91 \\
\text { (rs } 17886395)\end{array}$} \\
\hline $\mathrm{CC}$ & $3(1.4)$ & & & & & & & & & & & & & & \\
\hline CG & $57(25.7)$ & 50.8 & 8.5 & 10.2 & 5.1 & 3.4 & 22.0 & 0.33 & 54.2 & 18.6 & 6.8 & 3.4 & 8.5 & 8.5 & 0.23 \\
\hline GG & $162(73.0)$ & 49.1 & 15.1 & 8.2 & 5.7 & 5.0 & 17.0 & & 54.8 & 23.6 & 8.3 & 3.2 & 0.6 & 9.6 & \\
\hline \multicolumn{16}{|c|}{$\begin{array}{l}\text { aa } 140 \\
\text { (rs } \mid 965707)\end{array}$} \\
\hline $\mathrm{TT}$ & $13(5.8)$ & & & & & & & & & & & & & & \\
\hline $\mathrm{CT}$ & $87(38.8)$ & 53.1 & 15.3 & 8.2 & 2.0 & 2.0 & 19.4 & 0.15 & 53.1 & 24.5 & 10.2 & 3.1 & 2.0 & 7.1 & 0.24 \\
\hline $\mathrm{CC}$ & $124(55.4)$ & 45.9 & 12.3 & 9.0 & 8.2 & 6.6 & 18.0 & & 55.0 & 20.8 & 5.8 & 3.3 & 3.3 & 11.7 & \\
\hline \multicolumn{16}{|c|}{$\begin{array}{l}\text { aa } 223 \\
\text { (rs } 1965708)\end{array}$} \\
\hline$A A$ & $7(3.1)$ & & & & & & & & & & & & & & \\
\hline$A C$ & 7I (31.6) & 54.0 & 11.8 & 9.2 & 2.7 & 4.0 & 18.4 & 0.27 & 55.3 & 23.7 & 9.2 & 4.0 & 1.3 & 6.6 & 0.18 \\
\hline $\mathrm{CC}$ & 147 (65.3) & 46.9 & 14.5 & 8.3 & 6.9 & 4.8 & 18.6 & & 53.8 & 21.7 & 7.0 & 2.8 & 3.5 & 11.2 & \\
\hline
\end{tabular}

a $\mathrm{N}=22 \mathrm{I}$ infants had data for persistent cough and $\mathrm{N}=219$ for wheeze during the first year of life. ${ }^{\mathrm{b}} \mathrm{p}$-values from test for trend: Cochran-Armitage exact test ( $\mathrm{I}$-sided). Minor homozygotes and heterozygous alleles were combined and compared to the dominant homozygous group. Significant p-values $(\mathrm{p}<0.05)$ in bold-face type. c SNPs were in Hardy-Weinberg equilibrium. rs numbers are given in parentheses next to each amino acid. 
By convention, SFTPA1 and SFTPA2 allele haplotypes are denoted by $6 \mathrm{~A}^{\mathrm{n}}$ and $1 \mathrm{~A}^{\mathrm{m}}$ respectively $[17,21]$. The estimated frequency of each allele haplotype is given in Table 3. The five SNPs in SFTPA1 were in linkage disequilibrium as were the four SNPs in SFTPA2 ( $p<0.0001, \chi^{2}$ test of allelic associations).

The most common SFTPA1 allele haplotypes among white infants in our study population were $6 \mathrm{~A}^{2}, 6 \mathrm{~A}^{3}, 6 \mathrm{~A}^{4}$, and $6 \mathrm{~A}$ in order of decreasing frequency. All others made up $8 \%$ of the SFTPA1 alleles. $1 \mathrm{~A}^{0}$ was the most common SFTPA 2 allele followed in order by $1 \mathrm{~A}^{1}, 1 \mathrm{~A}^{2}, 1 \mathrm{~A}, 1 \mathrm{~A}^{5}, 1 \mathrm{~A}^{6}$, and $1 \mathrm{~A}^{3}$. All others combined made up $4 \%$ of the SFTPA2 alleles.
Significant associations were found between specific allele haplotypes and frequency of persistent cough or wheeze during the first year of life (Table 3). The 6A haplotype of SFTPA1 was a risk factor for both persistent cough and wheeze: infants with this haplotype (an estimated $6 \%$ of this group of white infants) were 3.7 to 4.7 times more likely to experience an additional week of persistent cough or wheeze, respectively, during their first year than infants without this haplotype.

SFTPA1 and SFTPA2 alleles are known to be in strong linkage disequilibrium $[24,25]$. This was also true in our population of white infants in a general test of allelic associations ( $\mathrm{p}<0.0001, \chi^{2}$ test), although pairwise linkage

Table 3: Unadjusted associations between surfactant protein A (SFTPA I,SFTPA2) haplotypes and persistent cough or wheeze in the first year of life. a Unadjusted odds ratios $(\mathrm{OR})$ and $95 \%$ confidence intervals $(\mathrm{Cl})$ are from ordered logistic regression models predicting symptom frequency. ${ }^{b}$ (CT and MA, $\left.1998-2000\right)$

\begin{tabular}{|c|c|c|c|c|c|c|c|c|}
\hline \multirow{2}{*}{$\begin{array}{l}\text { Allele, haplotype } \\
\text { SFTPAI }\end{array}$} & \multicolumn{5}{|c|}{ Nucleotide/amino acid } & \multirow{2}{*}{$\begin{array}{l}\text { Estimated Frequency } \\
\text { Distribution } \%(95 \% \mathrm{Cl})\end{array}$} & \multirow{2}{*}{$\begin{array}{l}\text { Persistent Cough } \\
\text { OR }(95 \% \mathrm{Cl})\end{array}$} & \multirow{2}{*}{$\begin{array}{c}\text { Wheeze } \\
\text { OR }(95 \% \mathrm{Cl})\end{array}$} \\
\hline & aa 19 & aa 50 & aa 62 & aa 133 & aa 219 & & & \\
\hline 6A & C/Ala & C/Leu & G & G & C/Arg & $6.1 \%(4.0-8.3)$ & $3.69(1.71,7.98)$ & $4.72(2.20,10.11)$ \\
\hline 6A $A^{2}$ & $\mathrm{~T} / \mathrm{Val}$ & $\mathrm{G} / \mathrm{Val}$ & A & $A$ & $\mathrm{C} / \mathrm{Arg}$ & $54.0 \%(49.3-58.7)$ & $1.18(0.63,2.19)$ & $1.13(0.60,2.14)$ \\
\hline $6 A^{3}$ & $\mathrm{~T} / \mathrm{Val}$ & C/Leu & A & $A$ & C/Arg & $25.6 \%(21.6-29.6)$ & $0.81(0.49,1.36)$ & $0.83(0.49,1.40)$ \\
\hline 6. $\mathbf{A}^{4}$ & $\mathrm{~T} / \mathrm{Val}$ & C/Leu & G & $A$ & $\mathrm{~T} / \mathrm{Trp}$ & $6.2 \%(4.1-8.4)$ & $0.94(0.44,2.03)$ & $0.70(0.31,1.60)$ \\
\hline all others & & & & & & $8 \%$ & & \\
\hline SFTPA2 & aa 9 & aa 91 & aa 140 & aa 223 & & & & \\
\hline IA & C/Thr & C/Pro & C & $\mathrm{C} / \mathrm{Gln}$ & & $8.4 \%(6.0-10.8)$ & $1.53(0.75,3.14)$ & $\mathrm{I} .30(0.63,2.7 \mathrm{I})$ \\
\hline $\mathbf{I A}^{0}$ & $\mathrm{~A} / \mathrm{Asn}$ & G/Ala & $\mathrm{C}$ & $\mathrm{C} / \mathrm{Gln}$ & & $54.2 \%(49.5-58.8)$ & $1.13(0.60,2.13)$ & $1.14(0.59,2.19)$ \\
\hline $\mid \mathbf{A}^{\mid}$ & C/Thr & G/Ala & $\mathrm{T}$ & A/Lys & & $13.7 \%(10.7-16.7)$ & $0.82(0.45,1.48)$ & $0.87(0.47,1.58)$ \\
\hline $\mathbf{I A}^{2}$ & C/Thr & G/Ala & $\mathrm{C}$ & C/Gln & & $10.2 \%(7.6-12.7)$ & $0.95(0.49,1.84)$ & $0.83(0.42,1.64)$ \\
\hline $\mathbf{I A}^{3}$ & $\mathrm{~A} /$ Asn & G/Ala & $\mathrm{T}$ & A/Lys & & $1.8 \%(0.7-2.9)$ & $0.45(0.08,2.48)$ & $0.55(0.10,3.06)$ \\
\hline $\mathbf{I A}^{5}$ & C/Thr & C/Pro & $\mathrm{T}$ & C/Gln & & $4.6 \%(2.7-6.5)$ & $0.43(0.15,1.23)$ & $0.66(0.24,1.79)$ \\
\hline $\mathbf{I A}^{6}$ & C/Thr & G/Ala & $\mathrm{T}$ & C/Gln & & $3.2 \%(1.7-4.7)$ & I.4I $(0.49,4.05)$ & I.54 $(0.54,4.39)$ \\
\hline all others & & & & & & $4 \%$ & & \\
\hline \multicolumn{9}{|l|}{ SFTPA Haplotype } \\
\hline 6A/IA & & & & & & $5.4 \%(3.2-7.2)$ & $3.20(1.39,7.36)$ & $3.25(1.43,7.37)$ \\
\hline $\mathbf{6 A}^{2} / 1 \mathbf{A}^{0}$ & & & & & & $49.0 \%(44.4-53.6)$ & $1.20(0.66,2.19)$ & $1.04(0.57,1.90)$ \\
\hline $6 A^{2} / 1 A^{2}$ & & & & & & $1.8 \%(0.6-2.9)$ & I.43 $(0.36,5.70)$ & $0.26(0.03,1.99)$ \\
\hline $6 \mathbf{A}^{2} / 1 \mathbf{A}^{3}$ & & & & & & $1.0 \%(0.2-1.9)$ & $0.65(0.10,4.39)$ & $0.79(0.11,5.47)$ \\
\hline $6 A^{3} / 1 A^{0}$ & & & & & & $4.7 \%(2.8-6.6)$ & $1.16(0.49,2.74)$ & $0.92(0.37,2.31)$ \\
\hline $6 A^{3} / 1 A^{1}$ & & & & & & $11.3 \%(8.5-14.1)$ & $1.12(0.60,2.08)$ & $1.08(0.57,2.04)$ \\
\hline $6 A^{3} / 1 A^{2}$ & & & & & & $5.6 \%(3.6-7.6)$ & $0.93(0.40,2.16)$ & $0.92(0.39,2.17)$ \\
\hline $6 A^{3} / 1 A^{6}$ & & & & & & $1.7 \%(0.5-2.8)$ & $0.91(0.21,4.07)$ & $2.26(0.55,9.33)$ \\
\hline $6 A^{4} / 1 A^{5}$ & & & & & & $2.9 \%(1.4-4.4)$ & $0.28(0.07,1.07)$ & $0.30(0.08,1.20)$ \\
\hline $6 A^{4} / 1 A^{6}$ & & & & & & $1.8 \%(0.6-3.0)$ & $1.88(0.49,7.16)$ & $1.69(0.44,6.39)$ \\
\hline Others & & & & & & $14.9 \%$ & & \\
\hline
\end{tabular}

aAnalyses included infants with complete data for both SFTPA alleles and respiratory symptoms, i.e., for SFTPAI and persistent cough ( $N=203)$ or wheeze $(N=202)$; SFTPA2 and persistent cough $(N=205)$ or wheeze $(N=204)$; SFTPA and persistent cough $(N=201)$ or wheeze $(N=200)$. bSeparate ordered logistic regression analyses were performed for each outcome measure and each haplotype with all other haplotypes serving as the reference group in each model. All model results $($ ORs $[95 \% \mathrm{Cl}]$ ) include estimates of model variabillity due to ambiguity in allele haplotype assignment (see text). Number of days per year of symptoms were included in models as a 6-category variable, i.e., 0, 1-7, 8-14, I5-21, 22-28, > 28 days. Significant results $(\mathrm{p}<0.05)$ are in bold-face type. c By convention, SFTPAI allele haplotypes are denoted by 6An and SFTPA2 allele haplotypes by $I A^{m}[\mid 7,2 I]$. daa 62 , aa $I 33$ and aa $I 40$ are silent. eEstimated frequency distribution of haplotypes (mean, $95 \% \mathrm{Cl}$ ) for white infants. 
disequilibrium measures $\left(\mathrm{r}^{2}\right)$ for SNPs within SFTPA reveal a spectrum of associations from $\mathrm{r}^{2}=0$ to 0.6 (Fig. 1). An examination of SFTPA1 and SFTPA2 alleles together indicates that infants with the $6 \mathrm{~A} / 1 \mathrm{~A}$ haplotype, an estimated $5.4 \%$ of this group, were over 3 times more likely to experience an additional week of persistent cough and/or wheeze during their first year than infants without this haplotype (Table 3 ).

\section{Discussion and conclusion}

Results from our study suggest that the 6A allele haplotype of SFTPA1 and the 6A/1A haplotype of SFTPA are associated with increased risk for wheeze and persistent cough among infants at risk for asthma. To our knowledge, this is the first study examining the association of polymorphisms in SFTPA with persistent cough and wheeze in infants. Respiratory symptoms may be triggered by bacterial or viral respiratory infections or exposure to environmental contaminants. This is certainly true for children in our birth cohort $[2,3,19]$. As reported previously [2], among all children in our birth cohort, infants whose mothers reported respiratory illnesses including bronchitis, bronchiolitis, pneumonia, or croup, were 3 to 5 times more likely to experience persistent cough or wheeze in the first year of life than infants who had no respiratory illness in their first year. Among these same infants, respiratory symptoms have also been linked to household exposures such as $\mathrm{NO}_{2}[3]$ and mold [2,19].

SFTPA likely plays multiple pleiotropic roles in the pathophysiology of the lung. Evidence from animal and human studies suggests an important role for SFTPA in protecting infants and young children during microbial infections early in life. SFTPA deficient mice are impaired in their ability to clear adenovirus from the lung [24]. SFTPA knockout mice show delayed clearance of Haemophilus influenzae [25]. Cell culture assays indicate that SFTPA enhances phagocytosis of $H$. influenzae and Streptococcus pneumoniae [26].

Among infants, polymorphisms in SFTPA have been associated with severe bronchiolitis [16]. The $6 \mathrm{~A}^{2} / 1 \mathrm{~A}^{3}$ haplotype was associated with increased risk of severe RSV infection (OR 10.4 95\% CI 1.3-83.2) and haplotype 6A/ $1 \mathrm{~A}$ was protective for severe disease (OR 0.17 95\% CI 0.04-0.80). In this study of Finnish infants, cases were hospitalized infants with documented bronchilotis caused by RSV. Controls, matched on sex and age, had no history of respiratory infections requiring hospitalization, but might have had respiratory infections (and symptoms) not requiring hospitalization. Although we identified $6 \mathrm{~A} / 1 \mathrm{~A}$ with increased risk for wheeze and persistent cough, it is interesting that the $6 \mathrm{~A} / 1 \mathrm{~A}$ haplotype is associated with respiratory problems in both populations. Direct comparison between the two studies is difficult because of differences in study design. In our study, "cases" were defined by reported respiratory symptoms. Specific causal agents were not identified, and we did not use hospitalization as a requirement for inclusion. Thus, some of our study subjects could resemble Finnish cases (hospitalized for RSV) or controls (not hospitalized, but possibly suffering from respiratory infection and exhibiting respiratory symptoms).

SFTPA has been shown to bind to aeroallergens including inhalable extracts from the mold Aspergillus fumigatus [27] and from the mite Dermatophagoides pteronyssinus (Der $p$ ) [28]. SFTPA has also been postulated to play a role in allergic asthma [29]. A murine model of asthma indicates that SFTPA mRNA and protein levels increase in response to allergen challenge [30]. SFTPA decreases Der $p$ induced lymphocyte proliferation and histamine release from the blood of atopic donors [31]. SFTPA has also been implicated in bronchial inflammation of sensitized mice [32].

All infants in our cohort have at least one sibling with asthma and one-third have asthmatic mothers (Table 1). Two-thirds of the infants have mothers with allergies (Table 1). The children in our cohort experienced high rates of wheeze $(46 \%)$ during their first year of life (Table 1). Among a cohort of 890 healthy infants in Connecticut and Virginia born between 1993-1996, 33\% experienced an episode of wheeze during the winter months of their first year of life [34]. The high rate of wheeze in our study population may reflect the special nature of our cohort: all are considered to be at risk for developing asthma. Along these same lines, SFTPA may play a role in the pathogenesis of asthma, and infants in our cohort, by virtue of their family histories of asthma, may differ in SFTPA1 and SFTPA2 hapylotype distributions compared to the general population. Population based estimates of SFTPA1 allele haplotype frequencies among white Americans are 56.2\% $6 \mathrm{~A}^{2}, 24.3 \% 6 \mathrm{~A}^{3}, 9.3 \% 6 \mathrm{~A}, 7.6 \% 6 \mathrm{~A}^{4}$ and $2.6 \%$ other [33]. Allele haplotype frequencies for SFTPA2 are $53 \% 1 \mathrm{~A}^{0}$, $10.2 \% 1 \mathrm{~A}, 14.3 \% 1 \mathrm{~A}^{1}, 7.6 \% 1 \mathrm{~A}^{2}$, and $14.9 \%$ all others [33]. With the notable exception of the SFTPA1 allele haplotype 6A, the distribution of SFTPA1 and SFTPA2 haplotypes in our sample of white infants is similar to that of white Americans in the general population. The general population frequency for $6 \mathrm{~A}$ of $9.3 \%$ is higher than the $95 \%$ confidence interval for our estimate of $6.1 \%$ (95\% CI 4.0-8.3), which may indicate a true difference in frequency for this allele haplotype among our group of infants.

The functional significance of specific changes in nucleotide sequence within SFTPA genes has not been well studied. SFTPA is a member of the collectin family and recognizes carbohydrates on the surface of pathogens via their carbohydrate recognition domain [35]. Allele 6A is 
the only common haplotype in our population with an alanine at aa 19 and a G at aa 133. The SNP at aa 133 is silent, however, aa 19 is in the $\mathrm{N}$ terminal region of SFTPA1 and an alanine in this region could conceivably impact binding to pathogens or aeroallergens. Further experiments are needed to identify whether amino acid changes in this region impact the biological properties of SFTPA. Alternatively, the 6A haplotype may simply be a marker for additional uncharacterized functional polymorphisms in our cohort.

Strengths of this study include the prospective study design and the well characterized demographic, illness, and environmental exposure information for the infant cohort. Mothers in this study were likely capable of accurately reporting respiratory symptoms due to their familiarity with wheeze and persistent cough in the older asthmatic child. Haplotype analyses often use the "most likely" haplotype and seldom include adjustments for uncertainty in haplotype assignment. We used regression calibration techniques that incorporate this uncertainty into estimates of the effect resulting in more conservative estimates of the true associations between SFTPA and persistent cough or wheeze during the first year of life.

Our results support the importance of SFTPA in modulating respiratory symptoms in infants. Persistent cough and wheeze may result from a variety of exposures and the multifunctional nature of SFTPA indicates that it protects the lung under a variety of conditions. The $6 \mathrm{~A} / 1 \mathrm{~A}$ haplotype may have a functional role in pathogenic processes, or may be linked to unmeasured markers that are causal. Future studies should replicate these observations and examine polymorphisms within SFTPA among additional racial and ethnic groups.

\section{Competing interests}

The author(s) declare that they have no competing interests.

\section{Authors' contributions}

MMP conceived of the study, analyzed and interpreted data, and drafted the manuscript. JFG participated in the analysis and interpretation of data, performed the statistical analysis, and helped revise the manuscript for important intellectual content. YZ was involved in the acquisition of data and provided technical support with the genotyping. EWT helped conceive the study, and was involved in the acquisition of data. $\mathrm{KB}$ conceived the study, participated in its design and coordination, and helped secure funding. TRH was involved in the critical revision of manuscript for important intellectual content and provided statistical expertise. MMB was involved in the study concept and design, study supervision, critical revisions of the manuscript for intellectual content, and helped obtain funding. BPL was involved in the study concept and design, study supervision, and obtained funding. All authors read and approved the final manuscript.

\section{Acknowledgements}

Written consent was obtained from the mothers to participate in this study. This study was made possible by the following hospitals from which our study participants were selected: Yale-New Haven, Danbury, Bridgeport, Hartford (CT), and Bay State (MA). We thank the original I,002 original families who participated in this study. This study was supported by grants ES07456 and ES054 10 from the National Institute of Environmental Health Sciences.

\section{References}

I. Morgan WJ, Stern DA, Sherrill DL, Guerra S, Holberg CJ, Guilbert TW, Taussig LM, Wright AL, Martinez FD: Outcome of asthma and wheezing in the first 6 years of life: follow-up through adolescence. American Journal of Respiratory \& Critical Care Medicine 2005, 172:1253-1258.

2. Belanger $K$, Beckett $W$, Triche $E$, Bracken MB, Holford T, Ren P, McSharry JJE, Gold DR, Platts-Mills TA, Leaderer BP: Symptoms of wheeze and persistent cough in the first year of life: associations with indoor allergens, air contaminants, and maternal history of asthma. American Journal of Epidemiology 2003, I58:| $95-202$.

3. van Strien RT, Gent JF, Belanger K, Triche E, Bracken MB, Leaderer BP: Exposure to NO2 and nitrous acid and respiratory symptoms in the first year of life. Epidemiology 2004, I 5:47I-478.

4. Ghildyal R, Hartley C, Varrasso A, Meanger J, Voelker DR, Anders EM, Mills J: Surfactant protein A binds to the fusion glycoprotein of respiratory syncytial virus and neutralizes virion infectivity. Journal of Infectious Diseases 1999, 180:2009-2013.

5. Benne CA, Kraaijeveld CA, van Strijp JA, Brouwer E, Harmsen M, Verhoef J, van Golde LM, van Iwaarden JF, lino $Y$ : Interactions of surfactant protein $A$ with influenza $A$ viruses: binding and neutralization. Journal of Infectious Diseases 1995, I 7 I:335-34 I.

6. LeVine AM, Gwozdz J, Stark J, Bruno M, Whitsett J, Korfhagen T: Surfactant protein-A enhances respiratory syncytial virus clearance in vivo. J Clin Invest 1999, 103:1015-1021.

7. LeVine AM, Kurak KE, Wright JR, Watford WT, Bruno MD, Ross GF, Whitsett JA, Korfhagen TR: Surfactant protein-A binds group B streptococcus enhancing phagocytosis and clearance from lungs of surfactant protein-A-deficient mice. American Journal of Respiratory Cell \& Molecular Biology 1999, 20:279-286.

8. Sano H, Kuroki Y: The lung collectins, SP-A and SP-D, modulate pulmonary innate immunity. Molecular Immunology 2005, 42:279-287.

9. Hohlfeld JM: The role of surfactant in asthma. Respiratory Research 2002, 3:4.

10. White RT, Damm D, Miller J, Spratt K, Schilling J, Hawgood S, Benson $B$, Cordell B: Isolation and characterization of the human pulmonary surfactant apoprotein gene. Nature 1985, 3 I 7:36 I-363.

II. Fisher JH, Kao FT, Jones C, White RT, Benson BJ, Mason RJ: The coding sequence for the 32,000-dalton pulmonary surfactant associated protein $A$ is located on chromosome 10 and identifies two separate restriction-fragment length polymorphisms. American Journal of Human Genetics 1987, 40:503-5 I I.

12. Kerr MH, Paton JY: Surfactant protein levels in severe respiratory syncytial virus infection. American Journal of Respiratory \& Critical Care Medicine 1999, I 59: III5-III8.

13. Haataja R, Ramet M, Marttila R, Hallman M: Surfactant proteins A and $B$ as interactive genetic determinants of neonatal respiratory distress syndrome. Human Molecular Genetics 2000, 9:275I-2760.

14. Marttila R, Haataja R, Guttentag S, Hallman M: Surfactant protein $A$ and $B$ genetic variants in respiratory distress syndrome in singletons and twins. American Journal of Respiratory and Critical Care Medicine 2003, I 68:1216-1222.

15. Marttila R, Haataja R, Ramet M, Pokela ML, Tammela O, Hallman M: Surfactant protein $A$ gene locus and respiratory distress syn- 
drome in Finnish premature twin pairs. Annals of Medicine 2003, 35:344-352.

16. Lofgren J, Ramet M, Renko M, Marttila R, Hallman M: Association between surfactant protein $A$ gene locus and severe respiratory syncytial virus infection in infants. Journal of Infectious Diseases 2002, 185:283-289.

17. Ramet M, Lofgren J, Alho OP, Hallman M: Surfactant protein-A gene locus associated with recurrent otitis media. Journal of Pediatrics 200I, 138:266-268.

18. Pettigrew MM, Gent JF, Zhu Y, Triche EW, Belanger KD, Holford TR, Bracken MB, Leaderer BP: Association of surfactant protein A polymorphisms with otitis media in infants at risk for asthma. BMC Medical Genetics 2006, 7:68.

19. Gent JF, Ren P, Belanger K, Triche E, Bracken MB, Holford TR, Leaderer BP: Levels of household mold associated with respiratory symptoms in the first year of life in a cohort at risk for asthma. Environmental Health Perspectives 2002, I I 0:A78I-6.

20. Pantelidis $\mathrm{P}$, Lagan AL, Davies JC, Welsh KI, du Bois RM: A single round PCR method for genotyping human surfactant protein (SP)-AI, SP-A2, and SP-D gene alleles. Tissue Antigens 2003, 6I:3|7-32I.

21. DiAngelo S, Lin Z, Wang G, Phillips S, Ramet M, Luo J, Floros J: Novel, non-radioactive, simple and multiplex PCR-cRFLP methods for genotyping human SP-A and SP-D marker alleles. Disease Markers 1999, I 5:269-28I.

22. Saxton AM: Genetic analysis of complext traits using SAS. Cary, NC, SAS Institute Inc.; 2004.

23. Carroll RJ, Ruppert D, Stefanski LA: Measurement error in nonlinear models. Boca Raton, Florida, Chapman and Hall/CRC Press; 1995.

24. Harrod KS, Trapnell BC, Otake K, Korfhagen TR, Whitsett JA: SP-A enhances viral clearance and inhibits inflammation after pulmonary adenoviral infection. American Journal of Physiology 1999, 277:580-588.

25. LeVine AM, Whitsett JA, Gwozdz JA, Richardson TR, Fisher JH, Burhans MS, Korfhagen TR: Distinct effects of surfactant protein $A$ or $\mathbf{D}$ deficiency during bacterial infection on the lung. Journal of Immunology 2000, 165:3934-3940.

26. Tino MJ, Wright JR: Surfactant protein A stimulates phagocytosis of specific pulmonary pathogens by alveolar macrophages. American Journal of Physiology 1996, 270:677-688.

27. Allen MJ, Harbeck R, Smith B, Voelker DR, Mason RJ: Binding of rat and human surfactant proteins $A$ and $D$ to Aspergillus fumigatus conidia. Infection \& Immunity 1999, 67:4563-4569.

28. Wang JY, Kishore U, Lim BL, Strong P, Reid KB: Interaction of human lung surfactant proteins $A$ and $D$ with mite (Dermatophagoides pteronyssinus) allergens. Clinical \& Experimental Immunology 1996, 106:367-373.

29. Hohlfeld JM, Erpenbeck VJ, Krug N: Surfactant proteins SP-A and SP-D as modulators of the allergic inflammation in asthma. Pathobiology 2003, 70:287-292.

30. Mishra A, Weaver TE, Beck DC, Rothenberg ME: Interleukin-5mediated allergic airway inflammation inhibits the human surfactant protein $C$ promoter in transgenic mice. Journal of Biological Chemistry 200I, 276:8453-8459.

31. Wang JY, Shieh CC, You PF, Lei HY, Reid KB: Inhibitory effect of pulmonary surfactant proteins $A$ and $D$ on allergen-induced lymphocyte proliferation and histamine release in children with asthma. American Journal of Respiratory \& Critical Care Medicine 1998, I 58:510-518.

32. Wang JY, Shieh CC, Yu CK, Lei HY: Allergen-induced bronchial inflammation is associated with decreased levels of surfactant proteins $A$ and $D$ in a murine model of asthma. Clinical and Experimental Allergy 200I, 31:652-662.

33. Triche EW, Belanger K, Beckett W, Bracken MB, Holford T, Gent J, Jankun T, McSharry JJE, Leaderer BP: Infant Respiratory Symptoms Associated with Indoor Heating Sources. American Journal of Respiratory and Critical Care Medicine 2002, I 66: I I05- I I I I.

34. Liu W, Bentley CM, Floros J: Study of human SP-A, SP-B and SP$D$ loci: allele frequencies, linkage disequilibrium and heterozygosity in different races and ethnic groups. BMC Genetics $2003,4: 13$.

35. Eggleton $P$, Reid KB: Lung surfactant proteins involved in innate immunity. Current Opinion in Immunology 1999, I I:28-33.

\section{Pre-publication history}

The pre-publication history for this paper can be accessed here:

http://www.biomedcentral.com/1471-2350/8/15/prepub
Publish with Biomed Central and every scientist can read your work free of charge

"BioMed Central will be the most significant development for disseminating the results of biomedical research in our lifetime. "

Sir Paul Nurse, Cancer Research UK

Your research papers will be:

- available free of charge to the entire biomedical community

- peer reviewed and published immediately upon acceptance

- cited in PubMed and archived on PubMed Central

- yours - you keep the copyright

Submit your manuscript here:

http://www.biomedcentral.com/info/publishing_adv.asp
BiolMedcentral 